\title{
Provider-to-Provider Electronic Communication in the Era of Meaningful Use: A Review of the Evidence
}

\author{
Colin Walsh, MD ${ }^{1,2 *}$, Eugenia L. Siegler, MD³ , Erin Cheston, MPA ${ }^{4}$, Heather O’Donnell, MD, MSc ${ }^{5}$, \\ Sarah Collins, RN, PhD ${ }^{6,7,8}$, Daniel Stein, MD, MA ${ }^{1}$, David K. Vawdrey, PhD1․ Peter D. Stetson, MD, MA ${ }^{1,2,4}$, \\ for the Informatics Intervention Research Collaboration (I2RC)
}

\begin{abstract}
${ }^{1}$ Department of Biomedical Informatics, Columbia University, New York, New York; ${ }^{2}$ Department of Medicine, Columbia University, New York, New York; ${ }^{3}$ Division of Geriatrics and Gerontology, Weill Cornell Medical College, New York, New York; ${ }^{4}$ ColumbiaDoctors, New York, New York; ${ }^{5}$ Depart-

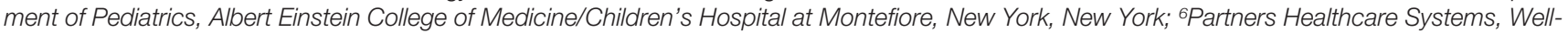
esley, Massachusetts; ${ }^{7 B}$ righam and Women's Hospital, Division of General Internal Medicine and Primary Care, Boston, Massachusetts; ${ }^{8}$ Harvard Medical School, Boston, Massachusetts.
\end{abstract}

BACKGROUND: Electronic communication between providers occurs daily in clinical practice but has not been well studied.

PURPOSE: To assess the impact of provider-to-provider electronic communication tools on communication and healthcare outcomes through literature review.

DATA SOURCES: Ovid MEDLINE, PubMed, Google Scholar, Cumulative Index to Nursing and Allied Health Literature, and Academic Search Premier.

STUDY SELECTION: Publication in English-language peerreviewed journals. Studies provided quantitative provider-toprovider communication data, provider satisfaction statistics, or electronic health record (EHR) communication data.

DATA EXTRACTION: Literature review.

DATA SYNTHESIS: Two reviewers conducted the title review to determine eligible studies from initial search results. Three reviewers independently reviewed titles, abstracts, and full text (where appropriate) against inclusion and exclusion criteria.

LIMITATIONS: Small number of eligible studies; few described trial design (20\%). Homogeneous provider type (physicians). English-only studies.

CONCLUSIONS: Of 25 included studies, all focused on physicians; most were observational (68\%). Most (60\%) described electronic specialist referral tools. Although overall use has been measured, there were no studies of the effectiveness of intra-EHR messaging. Literature describing the effectiveness of provider-to-provider electronic communications is sparse and narrow in scope. Complex care, such as that envisioned for the Patient Centered Medical Home, necessitates further research. Journal of Hospital Medicine 2013;8:589-597. (C) 2013 Society of Hospital Medicine

\section{INTRODUCTION}

Coordination of care within a practice, during transitions of care, and between primary and specialty care teams requires more than data exchange; it requires effective communication among healthcare providers. ${ }^{1-3}$ In clinical terms, data exchange, communication, and care coordination are related, but they represent distinct concepts. ${ }^{4}$ Data exchange refers to transfer of information between settings, independent of the individuals involved, whereas communication is the multistep process that enables information exchange between two people. ${ }^{5}$ Care coordination, as defined by O'Malley, is "integration of care in consultation with patients, their families and caregivers

\footnotetext{
*Address for correspondence and reprint requests: Colin Walsh, MD, Instructor in Clinical Medicine, Department of Medicine, Postdoctoral Fellow, Department of Biomedical Informatics, Columbia University, 622 W 168th St, VC5-538, New York, NY 10032; Telephone: 212-342-1644; Fax: 212-305-3302; E-mail: cgw2106@columbia.edu
}

Additional Supporting Information may be found in the online version of this article.

Revised: July 23, 2013; Accepted: July 31, 2013

2013 Society of Hospital Medicine DOI 10.1002/jhm.2082

Published online in Wiley Online Library (Wileyonlinelibrary.com). across all of a patient's conditions, needs, clinicians and settings." 3

Strong collaboration among providers has been associated with improved patient outcomes. ${ }^{2,6}$ Yet, despite the significant role of communication in healthcare, communication may not take place at all, even at high-stakes events like transitions of care, ${ }^{7,8}$ or it may be done poorly at the risk of substantial clinical morbidity and mortality. ${ }^{9-16}$

Proof of the global effectiveness of health information technology (HIT) to improve patient care is lacking, but data from some studies demonstrate real improvements in quality and safety in specific areas, ${ }^{17-19}$ especially with computerized physician order entry ${ }^{20}$ and electronic prescribing. ${ }^{21}$

The limited information about the effect of HIT on communication focuses largely on the anticipated improvements in patient-physician communication ${ }^{22-27}$; provider-to-provider communication within the electronic domain is not as well understood. A recent review of interventions involving communication devices such as pagers and mobile phones found limited high-quality evidence in the literature. ${ }^{28}$ Clinicians have described what they consider to be key characteristics of clinical electronic communications systems 
such as security/reliability, cross coverage, overall convenience, and message prioritization. ${ }^{29}$ Although the electronic health record (EHR) is expected to assist with this communication, ${ }^{30}$ it also has the potential to impede effective communication, leading physicians to resort to more traditional "workarounds." $31-33$

Measuring and improving the use of EHRs nationally were driving forces behind the creation of the Meaningful Use incentive program in the United States. ${ }^{34}$ To receive the incentive payments, providers must meet and report on a series of measures set in three stages over the course of five years. ${ }^{35}$ In the current state, Meaningful Use does not reward providerto-provider communication within the EHR. ${ }^{36,37}$ The main communication objectives for stages 1 and 2 concentrate on patient-to-provider communication, such as patient portals and patient-to-provider messaging. ${ }^{36,37}$

Understanding the current evidence for provider-toprovider communication within EHRs, its reported effectiveness, and its shortcomings may help to develop a roadmap for identifying next-generation solutions to support coordination of care. ${ }^{38,39}$ This review assesses the literature regarding provider-toprovider electronic communication tools (as supported within or external to an EHR). It is intended as a comprehensive view of studies reporting quantitative measures of the impact of electronic communication on providers and patients.

\section{METHODS}

\section{Definitions and Conceptual Model of Provider-to- Provider Communication}

We conducted a systematic review of studies of provider-to-provider electronic communication. This review included only formal clinical communication between providers and was informed by the Coiera communications paradigm. ${ }^{5}$ This paradigm consists of four steps: (1) task identification, when a task is identified and associated with the appropriate individual; (2) connection, when an attempt is made to contact that person; (3) communication, when task-specific information is exchanged between the parties; and (4) disconnection, when the task reaches some stage of completion.

\section{Literature Review}

We examined written electronic communication between providers including e-mail, text messaging, and instant messaging. We did not review provider-toprovider telephone or telehealth communication, as these are not generally supported within EHR systems. Communication in all clinical contexts was included among providers within an individual clinic or hospital and among providers across specialties or practice settings. ${ }^{40}$ We excluded physician handoff communication because it has been extensively reviewed elsewhere and because handoff occurs
TABLE 1. Search Strategies

\begin{tabular}{|c|c|c|}
\hline Database & Strategy & Items Reviewec \\
\hline Ovid MEDLINE & $\begin{array}{l}\text { Query terms: exp medicine/ or physicians or exp } \\
\text { outpatient clinics/ or exp hospitals/ AND } \\
\text { *communication/ or *computer communication } \\
\text { networks/ or *interprofessional relations/ or } \\
{ }^{*} \text { Continuity of patient care/ AND electronic } \\
\text { mail or referral and consultation or text } \\
\text { messaging/ or reminder systems. }\end{array}$ & 1513 \\
\hline PubMed & $\begin{array}{l}\text { Healthcare, provider, communication, messaging, } \\
\text { e-mail, texting, text messaging, instant } \\
\text { messaging, paging, coordination, referral, EHR, } \\
\text { EMR, electronic health record, electronic medical } \\
\text { record, electronic, and physician. Excluding } \\
\text { patient-provider and patient-physician }\end{array}$ & 340 \\
\hline Google Scholar & $\begin{array}{l}\text { Physician-physician electronic communication } \\
\text { excluding physician-patient }\end{array}$ & 940 \\
\hline CINAHL & $\begin{array}{l}\text { Medical records and communication; or } \\
\text { computerized patient records and communication }\end{array}$ & None \\
\hline Academic Search & Electronic health record and communication & 54 \\
\hline Premier (peer- & Communication and electronic health record & 80 \\
\hline reviewed & Physician-physician communication & 2 \\
\hline journals) & Physicians and electronic health records & 88 \\
\hline
\end{tabular}

NOTE: Abbreviations: CINAHL, Cumulative Index to Nursing and Allied Health Literature; EHR, electronic health record; EMR, electronic medical record; exp, explode. "Focus.

largely through verbal exchange not recorded in the EHR. ${ }^{41,42}$ Communication from clinical information systems to providers, such as automated notification of unacknowledged orders, was also excluded, as it is not within the scope of provider-to-provider interaction.

\section{Data Sources and Searches}

A comprehensive literature search was conducted in Ovid MEDLINE with the input of a medical librarian, and a parallel search was performed using PubMed. The Ovid MEDLINE query and parallel database search terms are documented in Table 1. Subsearches were conducted in Google Scholar, the Cumulative Index to Nursing and Allied Health Literature (CINAHL), and Academic Search Premier for peerreviewed journals. Subsequent studies citing the initially detected articles were found through citation maps.

\section{Study Selection \\ Paper Inclusion Criteria}

Requirements included publication in Englishlanguage peer-reviewed journals. Included studies provided quantitative provider-to-provider communication data, provider satisfaction statistics, or EHR communication data. Provider-to-staff communication was also included if it fell within the scope of studies of communication between providers.

\section{Paper Exclusion Criteria}

Studies excluded in this review were articles that reviewed EHR systems without any focus on 


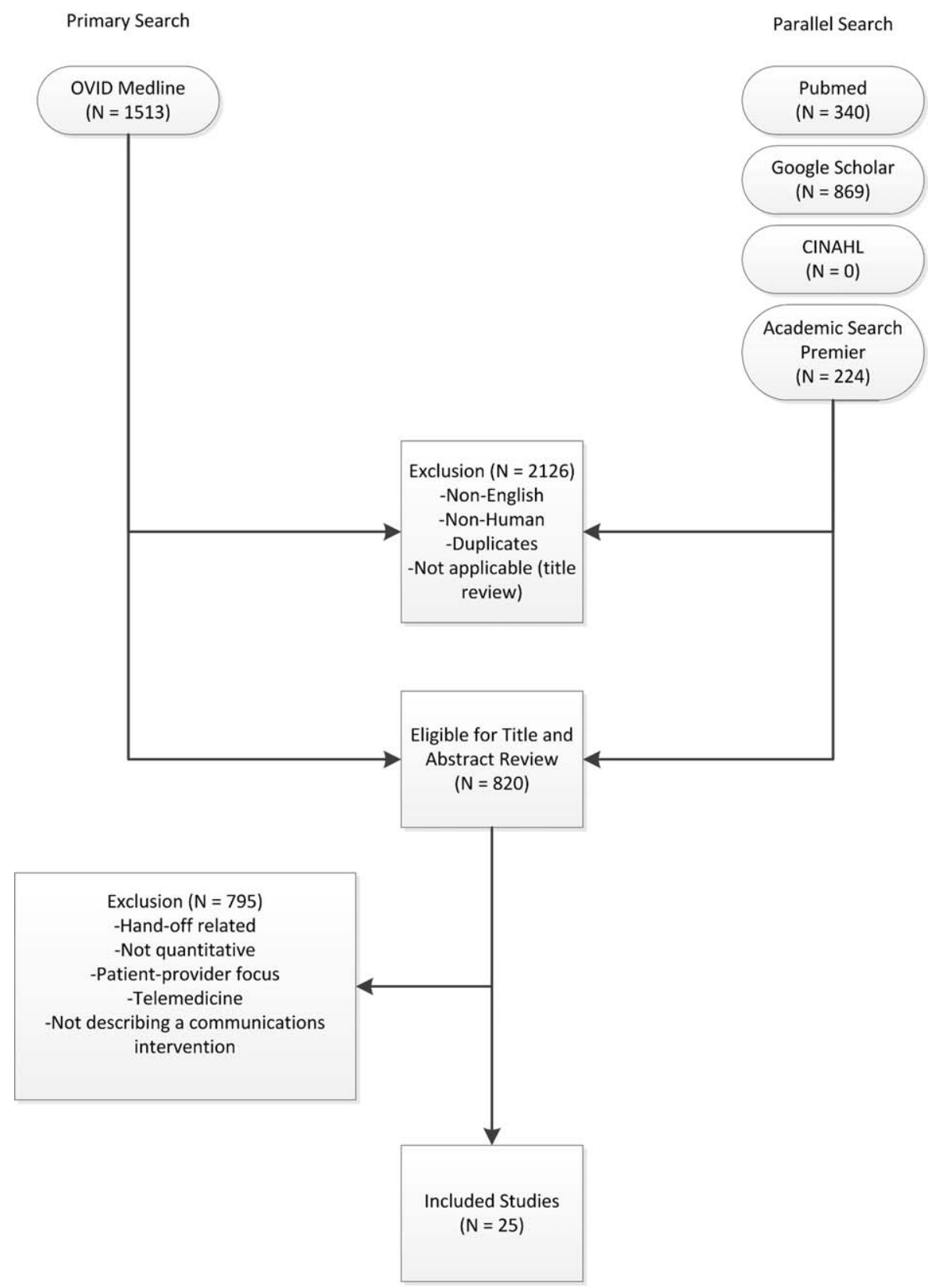

FIG. 1. Literature flow diagram. Abbreviations: CINAHL, Cumulative Index to Nursing and Allied Health Literature.

communication between providers and those that discussed EHR models and strategies but did not include actual testing and quantitative results. Results that included nontraditional online documents or that were found on non-peer-reviewed websites were also discarded. Duplicate records or publications that covered the same study were also removed. The most common reason for exclusion was the lack of quantitative evaluation.

\section{Data Extraction and Quality Assessment}

Three authors (Walsh, Siegler, Stetson) reviewed titles and abstracts of resultant studies against inclusion and exclusion criteria (Figure 1). Studies were evaluated qualitatively and findings summarized. Given the het- erogeneous nature of data reported, statistical analysis was not possible.

\section{RESULTS}

The primary and parallel searches produced 2946 results that were weaned through title review and exclusion of duplicates, non-English-language, and nonhuman studies to 820 articles for title and abstract review (Figure 1). After careful review of the articles' titles, abstracts, or full content (where appropriate), twenty-five articles met inclusion criteria and presented data about provider-to-provider electronic communication, either within an EHR or through a system designed to promote provider-to-provider communication. All of the studies that met inclusion 
TABLE 2. Studies of Electronic Provider-to-Provider Communication by Clinical Need

\begin{tabular}{|c|c|c|c|c|}
\hline Primary Author, Year & Design & Intervention & Measurement & Results \\
\hline \multicolumn{5}{|c|}{ Need: Communicate care across clinical settings (inpatient-outpatient) } \\
\hline Branger, $1992^{46}$ & Observational study & $\begin{array}{l}\text { Introduction of electronic messaging system } \\
\text { in the Netherlands between hospital and } \\
\text { PCPS. }\end{array}$ & $\begin{array}{l}\text { Satisfaction survey data using Likert scale of } \\
\text { "usefulness." }\end{array}$ & $\begin{array}{l}\text { Free text messaging to exchange patient data was rated } \\
\text { "very useful" or "useful" by } 20 \text { of } 27 \text { PCP respondents. }\end{array}$ \\
\hline Reponen, $2004^{66}$ & Observational study & $\begin{array}{l}\text { Finnish study of electronic referrals-XML } \\
\text { messages between EHRs or secure web } \\
\text { links. }\end{array}$ & $\begin{array}{l}\text { User questionnaire. No description of } \\
\text { respondents was provided. }\end{array}$ & $\begin{array}{l}\text { Internists surveyed estimated that electronic referrals } \\
\text { accelerate the referral process by } 1 \text { week. }\end{array}$ \\
\hline \multicolumn{5}{|c|}{ Need: Communicate care across specialties (primary care physicians-specialists) } \\
\hline Koojiman, $1998^{67}$ & Observational study & $\begin{array}{l}\text { Survey of } 45 \text { PCPs who received notes from } \\
\text { specialists via Electronic Data Interchange. }\end{array}$ & $\begin{array}{l}\text { User questionnaire with 5-point Likert scale of } \\
\text { satisfaction, from } 1 \text { ("much better") to } 5 \\
\text { ("much worse"). }\end{array}$ & $\begin{array}{l}\text { Highest satisfaction scores for speed (1.5-1.8) and efficiency } \\
(1.5-1.7) \text { for electronic messages, with lower scores for } \\
\text { reliability }(2.5-2.7) \text { and clarity }(2.5) \text {. }\end{array}$ \\
\hline Harno, $2000^{48}$ & Nonrandomized trial & $\begin{array}{l}\text { Eight-month prospective comparative study in } \\
\text { Finland of outpatient clinics in hospitals } \\
\text { with and without intranet referral systems. }\end{array}$ & $\begin{array}{l}\text { Comparison of numbers of electronic referrals, } \\
\text { clinic visits, costs. }\end{array}$ & $\begin{array}{l}\text { There were } 43 \% \text { of electronic referrals and } 79 \% \text { of outpatient } \\
\text { referrals that resulted in outpatient visits. A 3-fold } \\
\text { increase in productivity overall and 7-fold reduction in } \\
\text { visit costs per patient using e-mail consultation. }\end{array}$ \\
\hline Moorman, $2001^{47}$ & Observational study & $\begin{array}{l}\text { Supersedes Branger, } 1999 .{ }^{68} \text { Analyzes intra- } \\
\text { EHR communications between PCPs and } \\
\text { consultant in Netherlands re: diabetes } \\
\text { management of patients (1994-1998). }\end{array}$ & $\begin{array}{l}\text { Descriptive statistics of number of messages, } \\
\text { content, whether message had been copied } \\
\text { into EMR; survey of PCPS (12 of } 15 \\
\text { responded). }\end{array}$ & $\begin{array}{l}\text { Decline in integration by PCPs of messages in the EHR from } \\
75 \% \text { to } 51 \% \text { over first } 3 \text { years. Despite this, most PCPS } \\
\text { wanted to extend messaging to other patient groups. }\end{array}$ \\
\hline Bergus, $2006^{69}$ & Observational study & $\begin{array}{l}\text { Follow-up of Bergus, } 1998^{54} \text {; evaluated } \\
\text { formulation of clinical referrals to } \\
\text { specialists at the University of lowa by } \\
\text { retrospective review of e-mail transcripts. }\end{array}$ & $\begin{array}{l}\text { Analyzed taxonomy of clinical questions; } \\
\text { assessed need for clinical consultation of } \\
1618 \text { clinical questions. }\end{array}$ & $\begin{array}{l}\text { Specialists less likely to recommend clinic consultation if } \\
\text { referral specified the clinical task (OR: } 0.36, P<0.001) \text {, } \\
\text { intervention (OR: } 0.62, P=0.004) \text {, or outcome (OR: } 0.49 \text {, } \\
P<0.001) \text {. This effect was independent of clinical } \\
\text { content }(P>0.05 \text { ). }\end{array}$ \\
\hline Dennison, $2006^{70}$ & Pilot study & $\begin{array}{l}\text { Construction of an electronic referral pro } \\
\text { forma to facilitate referral of patients to } \\
\text { colorectal surgeons. }\end{array}$ & $\begin{array}{l}\text { Descriptive statistics. Comparisons of patient } \\
\text { attendance rate, delays to booking and to } \\
\text { actual appointment between } 54 \text { electronic } \\
\text { referrals and } 189 \text { paper referrals. }\end{array}$ & $\begin{array}{l}\text { Compared to paper referrals, electronic referrals were } \\
\text { booked more quickly (same day vs } 1 \text { week later on } \\
\text { average) and patients had lower nonattendance rates } \\
(8.5 \% \text { vs } 22.5 \%) \text {. Both results stated as statistically } \\
\text { significant, but } P \text { values were not provided. }\end{array}$ \\
\hline Shaw, $2007^{49}$ & Observational study & Dermatology electronic referral in England. & $\begin{array}{l}\text { Content of } 131 \text { electronic vs } 139 \text { paper referrals } \\
\text { to dermatologists(NHS Choose and Book). }{ }^{71}\end{array}$ & $\begin{array}{l}\text { Paper superior to electronic for clinical data such as current } \\
\text { treatments (included in } 68 \% \text { of paper vs } 39 \% \text { of } \\
\text { electronic referrals, } P<0.001 \text { ); electronic superior for } \\
\text { demographic data. }\end{array}$ \\
\hline Gandhi, $2008^{50}$ & Nonrandomized trial & $\begin{array}{l}\text { Electronic referral tool in the Partners } \\
\quad \text { Healthcare System in Massachusetts that } \\
\text { included a structured referral-letter gener- } \\
\text { ator and referral status tracker. Assigned } \\
\text { to } 1 \text { intervention site and } 1 \text { control site. }\end{array}$ & $\begin{array}{l}\text { Survey assessment. Fifty-four of } 117 \text { PCPs } \\
\quad \text { responded ( } 46 \%), 235 \text { of } 430 \text { specialists } \\
\text { responded (55\%), } 143 \text { out of } 210 \text { patients } \\
\text { responded (69\%). }\end{array}$ & $\begin{array}{l}\text { Intervention group showed high voluntary adoption (99\%), } \\
\text { higher information transfer rates prior to subspecialty } \\
\text { visit ( } 62 \% \text { vs } 12 \%) \text {, and lower rates of conflicting } \\
\text { information being given to patients ( } 6 \% \text { vs } 20 \% \text { ). }\end{array}$ \\
\hline
\end{tabular}

\begin{tabular}{|c|c|c|}
\hline John, $2008^{72}$ & Pilot study & $\begin{array}{l}\text { Validation study of the Lower Gastrointestinal } \\
\text { e-RP (through the Choose and Book Sys- } \\
\text { tem in the United Kingdom) intended to } \\
\text { improve yield of colon cancers diagnosed } \\
\text { and to reduce delays in diaanosis. }\end{array}$ \\
\hline Kim, 2009 $9^{73}$ & Observational study & $\begin{array}{l}\text { Electronic referrals via a portal to San } \\
\text { Francisco General Hospital. Included reply } \\
\text { functionality and ability to forward } \\
\text { messaging to a scheduler for calendaring. }\end{array}$ \\
\hline Scott, 2009 & Pilot study & $\begin{array}{l}\text { Pilot of urgent electronic referral system from } \\
\text { PCPs to oncologists at South West Wales } \\
\text { Cancer Centre. }\end{array}$ \\
\hline Were, $2009^{75}$ & Nonrandomized trial & $\begin{array}{l}\text { Geriatrics consultants were provided system } \\
\text { to make electronic recommendations } \\
\text { ("consultant-recommended orders") in the } \\
\text { native CPOE system along with consult } \\
\text { notes in the intervention vs consult notes } \\
\text { alone in the control. }\end{array}$ \\
\hline Dixon, $2010^{52}$ & Observational study & $\begin{array}{l}\text { Comparison of } 2 \text { extra-EHR systems (NHS } \\
\text { Choose and Book, Dutch ZorgDomein) for } \\
\text { booking referrals. Patients choose doctor } \\
\text { or hospital and the system transfers } \\
\text { demographic and clinical information } \\
\text { between PCP and specialist. }\end{array}$ \\
\hline Patterson, $2010^{51}$ & Observational study & $\begin{array}{l}\text { E-mail referral system to a neurologist in } \\
\text { Northern Ireland. Referrals were template } \\
\text { based and recorded as clinical episode in } \\
\text { the patient administration system. } \\
\text { Comparison of this system to conventional } \\
\text { referrals to another neurologist. }\end{array}$ \\
\hline Singh, $2011^{76}$ & Observational study & $\begin{array}{l}\text { Chart review of electronic referrals to } \\
\text { specialist practices in a Veterans Affairs } \\
\text { outpatient system. }\end{array}$ \\
\hline
\end{tabular}

Comparison of actual to simulated referral patterns through e-RP for 300 patients divided into colorectal cancer, "2-week wait" suspected cancer, and routine referral groups.

Impact of electronic referral system as measured by questionnaire to referring providers. $A$ total of 298/368 participated (24 clinics); $53.5 \%$ attending physicians.

Satisfaction statistics (10-point Likert scale) collected from PCPs via interview.

Rates of implementation of consultant recommendations. Qualitative survey of users of the new system.

e-RP was more accurate than traditional referral at upgrading patients who had cancer to the appropriate "suspected cancer" referral group ( $85 \%$ vs $43 \%, P=0.002)$.

Electronic referrals improved overall quality of care (reported by $72 \%)$, guidance of presubspecialty visit $(73 \%)$, and the ability to track referrals $(89 \%)$. Small change in access for urgent issues (35\% better, $49 \%$ reported no change).

Over 6 months, 99 referrals submitted; $81 \%$ were processed within 1 hour with high satisfaction scores.

Higher total number of recommendations (247 vs 192 , $P<0.05)$ and higher implementation rates of consultantrecommended orders in the intervention group vs control ( $78 \%$ vs $59 \%, P=0.01)$. High satisfaction scores on 5 point Likert scale for the intervention system with good survey response rate $(83 \%)$.

National data, patient and provider surveys, focus groups, observational studies. Focus was on patient choice, but evaluations included all aspects of the systems.

Resistance from PCPs during implementation; $78 \%$ of ZorgDomein PCPs felt referrals took more time; general displeasure on the part of specialists re: quality of referrals, although not quantified.

Evaluated effectiveness, cost, safety for period 2002-2007.

Decreased referral wait times ( 4 vs 13 weeks) and $35 \%$ cost reduction per patient for the e-mail referral vs conventional referrals.

№ diminution in safety. Limitation: single neurologist participated.

Follow-up actions taken by subspecialists within 30 days of receiving referral.

An intra-EHR referral system was still affected by communication breakdowns. 0 f 61,931 referrals, $36.4 \%$ were discontinued for inappropriate or incomplete referral requests. 
TABLE 2. Continued

\begin{tabular}{|c|c|c|c|c|}
\hline Primary Author, Year & Design & Intervention & Measurement & Results \\
\hline Kim-Hwang, $2010^{77}$ & Observational study & $\begin{array}{l}\text { Electronic referrals via a portal to San } \\
\text { Francisco General Hospital. Follow-up to } \\
\text { Kim, 2009. }\end{array}$ & $\begin{array}{l}\text { Survey of medical and surgical subspecialty } \\
\text { consultants. }\end{array}$ & $\begin{array}{l}\text { Statistically significant differences in clarity of consult } \\
\text { request in both medical and surgical clinics, in decreased } \\
\text { inappropriate referrals in surgical clinics, in decreased } \\
\text { use of follow-up appointments by surgical specialists, } \\
\text { and in decreased avoidable follow-up surgical visits. }\end{array}$ \\
\hline Warren, $2011^{53}$ & Observational study & $\begin{array}{l}\text { Electronic referrals from general medical } \\
\text { practices to public referral network of Hutt } \\
\text { Hospital in New Zealand (2007-2010). }\end{array}$ & $\begin{array}{l}\text { Retrospective analysis of transactional data from } \\
\text { messaging system and from general } \\
\text { inpatient tracking system. Qualitative data } \\
\text { collection via interviews. }\end{array}$ & $\begin{array}{l}\text { Estimated } 71 \% \text { of } 10,367 \text { referrals were electronic referrals } \\
\text { over } 3 \text { years. Statistically significant improvement in } \\
\text { referral latency without change in staffing. Clinicians } \\
\text { appreciate shared transparency of referrals but cite } \\
\text { usability issues as barriers. }\end{array}$ \\
\hline \multicolumn{5}{|c|}{ Need: Curbside consults (primary care physicians-specialists) } \\
\hline Bergus, $1998^{54}$ & Observational study & $\begin{array}{l}\text { Evaluation of the ECS for curbside } \\
\text { consultations between family physicians } \\
\text { and subspecialists. }\end{array}$ & $\begin{array}{l}\text { Descriptive statistics of usage data; survey of } \\
\text { users. }\end{array}$ & $\begin{array}{l}\text { Median response time } 16.1 \text { hours; } 92 \% \text { of questions } \\
\text { answered; almost } 90 \% \text { concerned specific patients. Both } \\
\text { groups expressed satisfaction. }\end{array}$ \\
\hline Abbott, $2002^{55}$ & Observational study & $\begin{array}{l}\text { Evaluation of Department of Defense "Ask a } \\
\text { Doc" physician-to-physicians e-mail con- } \\
\text { sultation system over network of } 21 \text { states } \\
\text { (1998-2000). }\end{array}$ & Descriptive statistics; qualitative assessment. & $\begin{array}{l}\text { There were } 3121 \text { consultations. Average response time }<12 \\
\text { hours. Minimal cost and effort to initiate and sustain. Felt } \\
\text { to mirror clinical practice. Barriers were security and } \\
\text { assignation of credit for consultation. }\end{array}$ \\
\hline \multicolumn{5}{|c|}{ Need: Communication of results (primary care physicians -specialists) } \\
\hline Singh, $2007^{56}$ & Nonrandomized trial & $\begin{array}{l}\text { Concurrent prospective evaluation of } \\
\text { responses to } 1017 \text { critical imaging alert } \\
\text { notifications in a Veterans Affairs } \\
\text { outpatient system (2006). Radiologists } \\
\text { generated alerts. Included receipt system. }\end{array}$ & $\begin{array}{l}\text { Measured percentage of unacknowledged alerts } \\
\text { and imaging lost to follow-up. }\end{array}$ & $\begin{array}{l}\text { There were } 368 \text { of } 1017 \text { transmitted alerts unacknowledged } \\
(36 \%) ; 45 \text { were completely lost to follow-up. There were } \\
0.2 \% \text { outpatient imaging results lost to follow-up overall. }\end{array}$ \\
\hline Singh, $2009^{57}$ & Nonrandomized trial & $\begin{array}{l}\text { Concurrent evaluation of responses to } 1196 \\
\text { critical imaging alert notifications in a } \\
\text { Veterans Affairs outpatient system (2007- } \\
\text { 2008). Similar coding system to Singh, } \\
2007.56\end{array}$ & $\begin{array}{l}\text { Measured percentage of alerts acknowledged, } \\
\text { timely follow-up; compared electronic alerts } \\
\text { alone to combination of alerts and phone } \\
\text { calls or admission. }\end{array}$ & $\begin{array}{l}\text { Percentage of alerts acknowledged did not differ by type of } \\
\text { communication; combination of electronic alerts with } \\
\text { phone follow-up (OR: } 0.12, P<0.001 \text { ) or admission (OR: } \\
0.22, P<0.001 \text { ) decreased likelihood of delayed follow- } \\
\text { up. Alerts to } 2 \text { providers increased the likelihood of } \\
\text { delayed follow-up (OR: } 1.99, P=0.03 \text { ). }\end{array}$ \\
\hline Abujudeh, $2009^{58}$ & Observational study & $\begin{array}{l}\text { Retrospective review of e-mail-based alert } \\
\text { system for abnormal imaging results at } \\
\text { Massachusetts General Hospital 2005- } \\
\text { 2007. E-mail alerting by radiologist to } \\
\text { ordering physician of nonurgent findings. }\end{array}$ & $\begin{array}{l}\text { Descriptive statistics; survey of referring } \\
\text { physicians (12/26). }\end{array}$ & $\begin{array}{l}\text { There were } 56,691 \text { out of 1,540,254 reports for important } \\
\text { but not urgent findings; } 93.3 \% \text { generated e-mail mes- } \\
\text { sage ( } 6.7 \% \text { failure rate); } 80 \% \text { of alerts were viewed. } \\
\text { Higher satisfaction for e-mail alerts over conventional } \\
\text { methods (eg, facsimile) for nonurgent but important } \\
\text { findings. }\end{array}$ \\
\hline \multicolumn{5}{|c|}{ Need: Communicate within 1 care setting (primary care physicians) } \\
\hline Lanham, $2012^{78}$ & Observational study & $\begin{array}{l}\text { Comparison of practice-level EHR use with } \\
\text { communication patterns among physi- } \\
\text { cians, nurses, medical assistants, practice } \\
\text { managers, and nonclinical staff within } \\
\text { individual practices in Texas. }\end{array}$ & $\begin{array}{l}\text { Observation and semistructured interviews. } \\
\text { Within-practice communication patterns } \\
\text { were categorized as fragmented or cohesive. } \\
\text { Practice-level EHR use was categorized as } \\
\text { homogeneous or heterogeneous. }\end{array}$ & $\begin{array}{l}\text { Clinical practices with cohesive within-practice communica- } \\
\text { tion patterns were associated with homogeneous pat- } \\
\text { terns of practice-level EHR use. }\end{array}$ \\
\hline Murphy, $2012^{79}$ & Observational study & $\begin{array}{l}\text { Review of note-based messaging within the } \\
\text { EHR in outpatient clinics of large tertiary } \\
\text { Veterans Affairs facility. Clinic staff send } \\
\text { "additional signature request" alerts linked } \\
\text { to parent notes in the EHR to primary care } \\
\text { physicians. }\end{array}$ & $\begin{array}{l}\text { Reason for and origin of alerts. Parent note } \\
\text { linked to alert was also reviewed for } 3 \text { "value } \\
\text { attributes": urgency; potential harm if alert } \\
\text { was missed; subjective value to PCP of the } \\
\text { alert. }\end{array}$ & $\begin{array}{l}\text { Of the alerts reviewed, } 53.7 \% \text { of } 525 \text { were deemed of "high } \\
\text { value" but required PCPs to review significant amounts of } \\
\text { extraneous text ( } 80.3 \% \text { of words in parent notes) to get } \\
\text { relevant information. Most alerts ( } 40 \% \text { ) were medication, } \\
\text { prescription, or refill related. }\end{array}$ \\
\hline
\end{tabular}

NOTE: Abbreviations: CPOE, computerized physician order entry; ECS, Email Consultation Service; EHR, electronic health record; EMR, electronic medical record; eRP, Electronic Referral Protocol; NHS, National Health Service; $\mathrm{OR}$, odds ratio; $\mathrm{PCP}$, primary care physician; $\mathrm{XML}$, extensible markup language.

criteria focused on physicians as providers. Five studies $(20 \%)$ described trial design, three $(12 \%)$ were pilot studies, and seventeen $(68 \%)$ were observational studies. Thirteen of twenty-five articles (52\%) described studies conducted in the United States and twelve in Europe.

Most of the studies $(56 \%)$ focused on electronic referrals between primary care and subspecialty providers. The clinical need was to communicate information on a specific patient with a specialist who shared responsibility for the overall plan of care. Only two studies evaluated "curbside consultation," where providers ask for clinical recommendations without formally engaging a specialist in the plan of care for a particular patient. Table 2 summarizes included studies and has been organized with respect to clinical need under evaluation. The major themes that emerged from this review included: studies of penetration of communication tools either within the EHR system (intra-EHR IT) or external to the EHR (extraEHR IT); electronic referrals; curbside consultations; and test results reporting (results notification). 


\section{Extra-EHR IT}

A review of electronic communication in 2000 examined electronic communication among primary care physicians but notably did not distinguish between communication and data exchange. ${ }^{43}$ Of the thirty included publications in that review, seventeen publications dealt with electronically communicated information in general; the remaining studies focused on notifications of test results or transitions of care, reports from specialists, or electronic communication as replacement of traditional referral. ${ }^{43}$ Although many studies of electronic communication described positive benefits, few included objective data, and most did not analyze provider-to-provider communication specifically. A survey of IT use outside of the EHR in 2006 documented that approximately $30 \%$ of clinicians used e-mail to communicate with other clinicians, fewer than those who consulted on-line journals $(40.8 \%)$, but many more than those who communicated with patients by e-mail at that time $(3.6 \%){ }^{44}$

\section{Intra-EHR IT}

A comparison of two physician surveys of EHR use in Massachusetts (the first in 2005 and the second in 2007) documented an increase in the percentage of practices with an EHR, from $23 \%$ to $35 \%$; in those practices with EHRs, only the use of electronic prescribing increased over time. Use of secure electronic referrals or messaging including secure e-mail remained unchanged; of note, referrals and messaging were considered a singular clinical function in that study. Between 2005 and 2007, referrals or clinical messaging were available in $62 \%$ and $63 \%$ of EHR systems, respectively, and they were used most or all of the time by $29 \%$ to $33 \%$ of the physicians who had an EHR. ${ }^{45}$

\section{Electronic Referrals}

Fourteen articles focused on electronic referrals. Two had a pre-post or longitudinal study design, ${ }^{46,47}$ and five included a control group. ${ }^{48-51}$ The rest were descriptive. In most cases, electronic referral improved the transfer of information, especially when standardized message templates were created. Use of electronic referral appeared to result in reduced waiting time for appointments and enabled more efficient triage.

Barriers to integration of electronic referral in the EHR were also assessed. An intra-EHR communication system requiring a primary care physician to integrate information e-mailed by the consultant into the record showed the percentage of integrated notes decreasing over time. ${ }^{47}$ Practitioners had mixed feelings about the system; although the majority $(92 \%$ of respondents) felt that the system improved patient care and wanted to extend messaging to other patient groups, they also felt that electronic messaging decreased the ease of reviewing data $(83 \%)$ and confused tasks and responsibilities (59\%). A study of British and Dutch electronic referral systems described significant resistance on the part of practitioners to electronic referrals and concern on the part of specialists about the quality of referrals. ${ }^{52}$ Another study demonstrated improvement in quality of demographic data but degradation in quality of clinical information when referrals were submitted electronically. ${ }^{49} \mathrm{~A}$ recent transactional analysis of electronic referrals in New Zealand showed high uptake and reduced referral latency compared to conventional referral; clinicians cited usability concerns as the major barrier to use. ${ }^{53}$

\section{Curbside Consultations via E-mail}

Two studies evaluated curbside consultations via email and documented high provider satisfaction and rapid turnaround. ${ }^{54,55}$ The preliminary nature of these studies raises questions of sustainability and long-term implementation.

\section{Results Notification}

Three studies focused on test-result reporting from radiologists. In these studies, a radiologist could designate a result as high priority and have an e-mail notification sent to the ordering physicians. ${ }^{56-58}$ Urgent results were relayed by telephone. Lack of acknowledgement of alerts impacted the results of every study, and in one of these studies, alerting two physicians, rather than just one, decreased the likelihood that the results would be followed up. ${ }^{57}$ Providers did prefer e-mail to fax notification. ${ }^{58}$

\section{DISCUSSION}

The principal findings of the literature review demonstrate the paucity of quantitative data surrounding provider-to-provider communication. The majority of studies focused on physicians as providers without emphasis on other provider types on the care team. Most of the quantitative studies investigated electronic referrals. Data collected largely represented measures of provider satisfaction and process measures. Few quantitative studies used established models or measures of team coordination or communication.

This study extends the work of others by compiling a comprehensive view of electronic provider-toprovider communication. A recent review of devices for clinical communication tells a part of the story, ${ }^{28}$ and our review adds a comprehensive, device-agnostic look at the systems physicians and other providers use every day.

Limitations of this review include the small number of eligible studies and a homogenous provider type (physicians). The latter is both an important finding and a limitation to generalizability of our results. Reviewed studies were in English only. The literature review by its nature is subject to publication bias.

Intra-EHR communication cannot serve all purposes, and is it not a panacea for effective care 
coordination. One recent qualitative study warns about the pitfalls of electronic communication. Interviews with physicians from twenty-six practices elicited some concerns about the resulting decrease in face-to-face communication that has resulted from the adoption of electronic communication tools. ${ }^{32}$ This finding brings implications: (1) a false sense of security may reduce verbal communications when they are needed most-during emergencies or when caring for complex patients who require detailed, nuanced discussion; and (2) fewer conversations within a practice can reduce both knowledge sharing and basic social interactions necessary for the maintenance of a collaboration. Last, privacy and confidentiality are top priorities. Common electronic communication tools are susceptible to security breaches, ${ }^{47,59}$ and innovations within this domain must conform to Health Insurance Portability and Accountability Act of 1996 and Health Information Technology for Economic and Clinical Health Act regulations. ${ }^{60}$

Although electronic communication is not a complete solution for clinical collaboration, it is difficult to use face-to-face communication and telephone communication to convey large amounts of patient information while simultaneously generating a record of the transaction. Moreover, paging functions, telephone calls, and face-to-face encounters can be highly interruptive, increasing cognitive load, burdening working memory, and shifting attention from the task at hand. ${ }^{14}$ Interruptions contribute to inefficiency and to the potential for errors. ${ }^{61}$

Effective coordination of care for the chronically ill is one of the essential goals of the health system; it is an ongoing process that depends on constant, effective communication. Bates and Bitton have recognized this and described the crucial role that HIT will play in creating an effective medical home by enumerating seven domains of HIT especially in need of research. ${ }^{62}$ In particular, they note that effective team care and care transitions will depend on an EHR that promotes both implicit and real-time communication: "it will be essential to develop communication tools that allow practices to record goals shared by providers and patients alike, and to track medical interventions and progress." 62

Future research could investigate a number of open questions. Overall, an emphasis should be placed on rigorous qualitative and quantitative evaluation of electronic communication. Process measures, such as length of stay, hospital readmission rates, and measures of care coordination, should be framed ultimately with respect to patient health outcomes. Such data are beginning to be reported. ${ }^{63}$

It is unclear which types of communications would be best served within the EHR and which should remain external to it. Instant communication or "chat" has not been studied sufficiently to show a demonstrable impact on patient care. Cross-coverage and team identification within the EHR can be further studied with respect to workflows and best practices. Studies using structured observation or time-andmotion analysis could provide insight into use cases and workflows that providers implement to discuss patients. Future research should incorporate established models of communication ${ }^{5}$ and coordination. ${ }^{64}$ Data on unintended consequences or harms of provider-to-provider electronic communication have been limited, and this area should be considered in subsequent work. Finally, although the scope of this review focused on communication between providers, transformative electronic communication systems should bridge communication gaps between providers and patients as well.

As adoption of EHRs in US hospitals has increased from $15.1 \%$ of US hospitals in 2010 to $26.6 \%$ in 2011 for any type of EHR and $3.6 \%$ to $8.7 \%$ for comprehensive EHRs, ${ }^{65}$ it is worth noting that Meaningful Use, as it stands, incentivizes patient-provider communication, but not communication between providers. Inclusion of certification criteria focused on provider-to-provider communication may spur additional innovation.

\section{CONCLUSIONS}

The optimal features to support electronic communication between providers remain under-assessed, although there is preliminary evidence for the acceptability of electronic referrals. Without better understanding of electronic communication on workflow, provider satisfaction, and patient outcomes, the impact of such tools on coordination of complex medical care will be an open question, and it remains an important one to answer.

\section{Acknowledgments}

The authors would like to express their gratitude to Dr. Thomas Payne, Medical Director of IT Services at the University of Washington, for sharing his expertise, and to Marina Chilov, medical librarian at Columbia University, for her assistance with the literature search. The authors would like to thank Paul Sun, MA, for his assistance with the literature review.

Disclosures: This work was funded by 5K22LM8805 (PDS) and T15 LM007079 (CW, SC) grants. Dr. Stetson serves on the advisory board of the Allscripts Enterprise EHR.

\section{References}

1. Dunn AS, Markoff B. Physician-physician communication: what's the hang-up? J Gen Intern Med. 2009;24:437-439.

2. Foy R, Hempel S, Rubenstein L, et al. Meta-analysis: effect of interactive communication between collaborating primary care physicians and specialists. Ann Intern Med. 2010;152(4):247-258.

3. O'Malley AS, Grossman JM, Cohen GR, Kemper NM, Pham HH. Are electronic medical records helpful for care coordination? Experiences of physician practices. J Gen Intern Med. 2009;25:177-185.

4. Stetson PD, McKnight LK, Bakken S, Curran C, Kubose TT, Cimino JJ. Development of an ontology to model medical errors, information needs, and the clinical communication space. Proc AMIA Symp. 2001:672-676.

5. Coiera E. Clinical communication: a new informatics paradigm. Proc AMIA Annu Fall Symp. 1996:17-21.

6. Zwarenstein M, Goldman J, Reeves S. Interprofessional collaboration: effects of practice-based interventions on professional practice and healthcare outcomes. Cochrane Database Syst Rev. 2009;(3): CD000072. 
7. Pantilat SZ, Lindenauer PK, Katz PP, Wachter RM. Primary care physician attitudes regarding communication with hospitalists. Dis Mon. 2002;48(4):218-229.

8. Bell CM, Schnipper JL, Auerbach AD, et al. Association of communication between hospital-based physicians and primary care providers with patient outcomes. J Gen Intern Med. 2009;24(3):381-386.

9. Bates DW, Leape LL, Cullen DJ, et al. Effect of computerized physician order entry and a team intervention on prevention of serious medication errors. JAMA. 1998;280(15):1311-1316.

10. Bhasale AL, Miller GC, Reid SE, Britt HC. Analysing potential harm in Australian general practice: an incident-monitoring study. $J \mathrm{Am}$ Med Inform Assoc. 1998;169:73-76.

11. Coiera E. When conversation is better than computation. I Am Med Inform Assoc. 2000;7(3):277-286.

12. Coiera EW, Jayasuriya RA, Hardy J, Bannan A, Thorpe ME. Communication loads on clinical staff in the emergency department. $J \mathrm{Am}$ Med Inform Assoc. 2002;176(9):415-418.

13. Kripliani S, LeFevre F, Phillips CO, Williams MV, Basaviah P, Baker DW. Deficit in communicaiton and information transfer between hospital-based and primary care physicians. JAMA. 2007;297:831841.

14. Parker J, Coiera E. Improving clinical communication: a view from psychology. I Am Med Inform Assoc. 2000;7(5):453-461.

15. Sutcliffe KM, Lewton E, Rosenthal MM. Communication failures: an insidious contributor to medical mishaps. Acad Med. 2004;79(2): 186-194.

16. Wilson RM, Runciman WB, Gibberd RW, Harrison BT, Newby L, Hamilton JD. The Quality in Australian Health Care Study. Med J Aust. 1995;163:458-471.

17. Chaudhry B, Wang J, Wu S, et al. Systematic review: impact of health information technology on quality, efficiency, and costs of medical care. Ann Intern Med. 2006;144(10):742-752.

18. Shekelle PG, Morton SC, Keeler EB. Costs and benefits of health information technology. Evid Rep Technol Assess. 2006;132:1-71.

19. Poon EG, Wright A, Simon SR, et al. Relationship between use of electronic health record features and health care quality: results of a statewide survey. Med Care. 2010;48:203-209.

20. Longhurst CA, Parast L, Sandborg CI, et al. Decrease in hospital-wide mortality rate after implementation of a commercially sold computerized physician order entry system. Pediatrics. 2010;126:e1-e8.

21. Kaushal R, Kern LM, Barron Y, Quaresimo J, Abramson EL. Electronic prescribing improves medication safety in community-based office practices. J Gen Intern Med. 2010;25:530-536.

22. Reynolds A. Patient-centered Care. Radiol Technol. 2009;81(2):133147.

23. Tang PC, Lansky D. The missing link: bridging the patient-provider health information gap. Health Aff (Millwood). 2005;24(5):12901295.

24. Tang PC, Ash JS, Bates DW, Overhage JM, Sands DZ. Personal health records: definitions, benefits, and strategies for overcoming barriers to adoption. I Am Med Inform Assoc. 2006;13(2):121-126.

25. Liederman EM, Morefield CS. Web messaging: a new tool for patientphysician communication. I Am Med Inform Assoc. 2003;10(3):260270

26. Prady SL, Norris D, Lester JE, Hoch DB. Expanding the guidelines for electronic communication with patients. I Am Med Inform Assoc. 2001;8(4):344-348.

27. Neill RA, Mainous AG III, Clark JR, Hagen MD. The utility of electronic mail as a medium for patient-physician communication. Arch Fam Med. 1994;3(3):268-271.

28. Wu RC, Tran K, Lo V, et al. Effects of clinical communication interventions in hospitals: a systematic review of information and communication technology adoptions for improved communication between clinicians. Int J Med Inform. 2012;81(11):723-732.

29. Sarkar IN, Starren J. Desiderata for personal electronic communication in clinical systems. I Am Med Inform Assoc. 2002;9(3): 209-216.

30. Coiera E. When conversation is better than computation. J Am Med Inform Assoc. 2000;7:277-286.

31. Bates DW. Getting in step: electronic health records and their role in care coordination. J Gen Intern Med. 2010;25:174-176.

32. O'Malley AS, Cohen GR, Grossman JM. Electronic medical records and communication with patients and other clinicians: are we talking less? Issue Brief Cent Stud Health Syst Change. 2010;(131):1-4.

33. O’Malley AS, Reschovsky JD. Referral and consultation communication between primary care and specialist physicians: finding common ground. Arch Intern Med. 2011;171(1):56-65.

34. Blumenthal D, Tavenner M. The "meaningful use" regulation for electronic health records. N Engl J Med. 2010;363(6):501-504.

35. Centers for Medicare \& Medicaid Services. EHR incentive program. 2012. Available at: https://www.cms.gov/Regulations-and-Guidance/ Legislation/EHRIncentivePrograms/Meaningful_Use.html. Accessed July 30, 2012.

36. Centers for Medicare \& Medicaid Services. Meaningful use measures. 2012. Available at: https://www.cms.gov/Regulations-and-Guidance/
Legislation/EHRIncentivePrograms/downloads/EP-MU-TOC.pdf. Accessed July 30, 2012.

37. Centers for Medicare and Medicaid Services. Electronic health record incentive program-stage 2. Fed Regist. 2012:53967-54162.

38. O'Malley AS, Grossman JM, Cohen GR, Kemper NM, Pham HH. Are electronic medical records helpful for care coordination? Experiences of physician practices. J Gen Intern Med. 2010;25(3):177-185.

39. Bates DW. Getting in step: electronic health records and their role in care coordination. I Gen Intern Med. 2010;25(3):174-176.

40. Jirjis J, Weiss JB, Giuse D, Rosenbloom ST. A framework for clinical communication supporting healthcare delivery. AMIA Annu Symp Proc. 2005:375-379.

41. Understanding and improving patient handoffs. It Comm J Qual Improv. 2010:49-96.

42. Stein DM, Wrenn JO, Johnson SB, Stetson PD. Signout: a collaborative document with implications for the future of clinical information systems. AMIA Annu Symp Proc. 2007:696-700.

43. van der Kam WJ, Moorman PW, Koppejan-Mulder MJ. Effects of electronic communication in general practice. Int $J$ Med Inform. 2000;60(1):59-70.

44. Grant RW, Campbell EG, Gruen RL, Ferris TG, Blumenthal D. Prevalence of basic information technology use by U.S. physicians. J Gen Intern Med. 2006;21:1150-1155.

45. Simon SR, Soran CS, Kaushal R, et al. Physicians' use of key functions in electronic health records from 2005 to 2007: a statewide survey. J Am Med Inform Assoc. 2009;16:465-470.

46. Branger PJ, Wouden JCVd, Schudel BR, et al. Electronic communication between providers of primary and secondary care. BMJ. 1992; 305(6861):1068-1070.

47. Moorman PW, Branger PJ, van der Kam WJ, van der Lei J. Electronic messaging between primary and secondary care: a four-year case report. I Am Med Inform Assoc. 2001;8(4):372-378.

48. Harno K, Paavola T, Carlson C, Viikinkoski P. Patient referral by telemedicine: effectiveness and cost anslysis of an intranet system. $J$ Telemed Telecare. 2000;6(6):320-329.

49. Shaw LJ, de Berker D. Strengths and weaknesses of electronic referral: comparison of data content and clinical value of electronic and paper referrals in dermatology. Br J Gen Pract. 2007;57(536):223-224.

50. Gandhi TK, Keating NL, Ditmore M, et al. Improving referral communication using a referral tool within an electronic medical record. In: Henriksen K, Battles JB, Keyes MA, Grady ML, eds. Advances in Patient Safety: New Directions and Alternative Approaches. Vol. 3. Performance and Tools. Rockville, MD: Agency for Healthcare Research and Quality; 2008:63-74.

51. Patterson V, Humphreys J, Henderson M, Crealey G. Email triage is an effective, efficient, and safe way of managing new referrals to a neurologist. Qual Safety Health Care. 2010;19(5):e51.

52. Dixon A, Robertson R, Bal R. The experience of implementing choice at point of referral: a comparison of the Netherlands and England. Health Econ Policy Law. 2010;13:1-23.

53. Warren J, White S, Day KJ, Gu Y, Pollock M. Introduction of electronic referral from community associated with more timely review by secondary services. Appl Clin Inform. 2011;2(4):546-564.

54. Bergus GR, Sinift SD, Randall CS, Rosenthal DM. Use of an e-mail curbside consultation service by family physicians. J Fam Pract. 1998; 47:357-360.

55. Abbott KC, Mann S, DeWitt D, Sales LY, Kennedy S, Poropatich RK. Physician-to-physician consultation via electronic mail: the Walter Reed Army Medical Center Ask a Doc system. Mil Med. 2002;167: 200-204.

56. Singh H, Arora H, Vij MS, Rao R, Khan MM, Petersen LA. Communication outcomes of critical imaging results in a computerized notification system. I Am Med Inform Assoc. 2007;14:459-466.

57. Singh H, Thomas EJ, Mani S, et al. Timely follow-up of abnormal diagnostic imaging test results in an outpatient setting: are electronic medical records achieving their potential? Arch of Intern Med. 2009; 169(17):1578-1586.

58. Abujudeh HH, Kaewlai R, Choy G, Whelton DG, Rosenthal DI. Important imaging finding e-mail alert system: experience after 3 years of implementation. Radiology. 2009;252:747-753.

59. Hindocha N. Instant insecurity: security issues of instant messaging. Symantec website. Available at: http://www.symantec.com/connect/ articles/instant-insecurity-security-issues-instant-messaging.

60. Janacek B. Secure messaging in healthcare. Tech solutions for HIPAAcompliant messaging. J AHIMA. 2008;79(6):50-51.

61. Westbrook JI, Woods A, Rob MI, Dunsmuir WT, Day RO. Association of interruptions with an increased risk and severity of medication administration errors. Arch Intern Med. 2010;170(8):683-690.

62. Bates DW, Bitton A. The future of health information technology in the patient-centered medical home. Health Aff (Millwood). 2010; 29(4):614-621.

63. Chen AH, Murphy EJ, Yee HF Jr. eReferral-a new model for integrated care. N Engl J Med. 2013;368(26):2450-2453.

64. McDonald KM, Sundaram V, Bravata DM, et al. Closing the Quality Gap: A Critical Analysis of Quality Improvement Strategies. Vol 7. Care Coordination. Rockville, MD; 2007. 
65. DesRoches CM, Worzala C, Joshi MS, Kralovec PD, Jha AK. Small, nonteaching, and rural hospitals continue to be slow in adopting electronic health record systems. Health Aff (Millwood). 2012;31(5): 1092-1099.

66. Reponen J, Marttila E, Paajanen H, Turula A. Extending a multimedia medical record to a regional service with electronic referral and discharge letters. I Telemed Telecare. 2004;10S:81-83.

67. Kooijman CJ, Kaag ME. Sending specialist reports to GPs using EDI. Stud Health Tech Inform. 1998;52(pt 1):408-411.

68. Branger PJ, van't Hooft A, van der Wouden JC, Moorman PW, van Bemmel JH. Shared care for diabetes: supporting communication between primary and secondary care. Int J Med Inform. 1999;53(23):133-142.

69. Bergus GR, Emerson M, Reed DA, Attaluri A. Email teleconsultations: well formulated clinical referrals reduce the need for clinic consultation. J Telemed Telecare. 2006;12(1):33-38.

70. Dennison J, Eisen S, Towers M, Ingham Clark C. An effective electronic surgical referral system. Ann R Coll Surg Engl. 2006;88(6): 554-556.

71. Walford S. Choose and book. Clin Med. 2006;6(5):473-476.

72. John SKP, George S, Primrose JN, Fozard BJ. Validation of the lower gastrointestinal electronic referral protocol. Brit J Surg. 2008;95:506514.
73. Kim Y, Chen AH, Keith E, Yee HF, Kushel MB. Not perfect, but better: primary care providers' experiences with electronic referrals in a safety net health system. J Gen Intern Med. 2009;24:614-619.

74. Scott K. The Swansea electronic referrals project. J Telemed Telecare. 2009;15:156-158.

75. Were MC, Abernathy G, Hui SL, Kempf C, Weiner M. Using computerized provider order entry and clinical decision support to improve referring physicians' implementation of consultants' medical recommendations. J Am Med Inform Assoc. 2009;16(2):196-202.

76. Singh H, Esquivel A, Sittig DF, et al. Follow-up actions on electronic referral communication in a multispecialty outpatient setting. J Gen Intern Med. 2011;26(1):64-69.

77. Kim-Hwang JE, Chen AH, Bell DS, Guzman D, Yee HF, Kushel MB. Evaluating electronic referrals for specialty care at a public hospital. J Gen Intern Med. 2010;25(10):1123-11028.

78. Lanham HJ, Leykum LK, McDaniel RR Jr. Same organization, same electronic health records (EHRs) system, different use: exploring the linkage between practice member communication patterns and EHR use patterns in an ambulatory care setting. J Am Med Inform Assoc. 2012;19(3):382-391.

79. Murphy DR, Reis B, Kadiyala H, et al. Electronic health record-based messages to primary care providers: valuable information or just noise? Arch Intern Med. 2012;172(3):283-285. 